\title{
Association of serum deiodinase type 2 level with chronic obstructive pulmonary disease in the Polish population
}

\author{
Elżbieta Gałecka® ${ }^{\circledR}$, Anna Kumor-Kisielewska and Paweł Górski \\ Department of Pulmonology and Allergology, Medical University of Lodz, Łódź, Poland
}

\begin{abstract}
Backgrounds: Deiodinase type 2 (DIO2) is a selenoenzyme involved in the synthesis of thyroid hormones. Chemerin is a newly investigated adipokine known also as novel chemokine. Both molecules have been recently expected and found to play an important role in inflammation and immunity. DIO2, for example, is upregulated during acute and chronic inflammation. In addition, inflammation-induced expression of $\mathrm{DIO} 2$ in macrophages has been confirmed, while chemerin modulates the activation and chemotaxis of immune cells. It is widely known that chronic obstructive pulmonary disease (COPD) - the most common lung disease in the world - is accompanied by an inflammatory process and immune activation. There are no studies demonstrating an association between DIO2, chemerin and COPD. The aim of this study was to estimate $\mathrm{DIO} 2$ and chemerin concentration in serum collected from patients suffering from COPD and to compare it with healthy subjects, as well as to correlate with basic and clinical characteristics. Methods: The study group included 50 patients with COPD and 30 healthy subjects. DIO2 and chemerin serum levels as well as c-reactive protein levels were determined in all the subjects using commercial enzymelinked immunosorbent assay kits. The association between serum DIO2 and chemerin with sociodemographic and clinical variables was assessed. Results: DIO2 serum levels were significantly higher in the patients with COPD as compared to the control group $(50.3 \pm 23.2 \mathrm{U} / \mathrm{L}$ vs. $13.3 \pm 13.1 ; p<0.00001)$. No differences were observed in serum chemerin levels between the patients and controls (107.559 \pm 86.695 .6 vs. $100.701 \pm 53.805 ; p=0.54)$. Furthermore, there was no association between $\mathrm{DIO} 2$ and chemerin levels and other variables, and no correlation between both molecules. Conclusions: This study demonstrated that DIO2 levels were higher in the patients with COPD than in the control subjects. The examined molecules should be further investigated if they are intended to be considered markers of processes involved in COPD mechanisms.
\end{abstract}

Key words: deiodinase type 2, chemerin, COPD

Received: 08 January, 2019; revised: 18 February, 2019; accepted: 11 March, 2019; available on-line: 12 April, 2019

⿶e-mail: galeckaela@wp.pl

Acknowledgements of Financial Support: This study was supported with funding from the scientific research grant of the Polish National Science Center (Decision No. 2012/07/B/NZ7/04212) and regular finances of the Department of Pneumonology and Allergy, Medical University of Lodz, Poland (503/1-151-03).

Abbreviations: $\mathrm{BMI}$, Body mass index; $\mathrm{BAL}$, bronchoalveolar lavage; COPD, Chronic obstructive pulmonary disease; CS, cigarette smoke; CRP, C-reactive protein; DIO2, deiodinase type 2; FEV1, forsed expiratory volume in 1 second; FVC, Forced Vital Capacity; DIOs, iodothyronine deiodinases; LPS, Lipopolysaccharide; GOLD,
Global Initiative for Chronic Obstructive Lung Disease; TH, thyroid hormones; WHR, waist-to-hip ratio; WT, wais wild type

\section{INTRODUCTION}

Chronic obstructive pulmonary disease (COPD) is an important cause of mortality and morbidity worldwide and is becoming a major public health problem (Lopez-Campos et al., 2016). The disease is a result of many complex gene-environment interactions and is characterized by an unclear and multidirectional background; it is also considered to be a multicomponent disease (Mayer \& Newman, 2001)

Large number of data have demonstrated that a chronic and systemic inflammation reaction and their components may participate in the patomechanism of COPD, and that signs of inflammation are also characteristic for individuals suffering from this disease (Sinden \& Stockley, 2010).

Inflammation is orchestrated by many factors. One of them is the adipose tissue, which produces mediators, such as adipokines, involved in many chronic inflammatory diseases, including COPD (Fantuzzi, 2005).

Chemerin, which is found in the liver, the white fat tissue, lung, heart, and immune cells, is one of the newly discovered adipokines, also known as adipocytokines (Fatima et al., 2014). Chemerin plays a role of an immunomodulating factor, the regulation of which is under the influence of, for example, IL-1, IL-6, TNF- $\alpha$ and other proinflammatory molecules. As a Chemerin as a ligand of chemerin-like receptor participates in inflammation from its first acute phase and in its reduction. The process through which chemerin is involved in inflammation is the induction of chemotaxis of immune cells, such as natural killers, macrophages, dendritic cells, and neutrophils (Mariani \& Roncucci, 2015). Increased levels of chemerin concentration in the serum are observed in various diseases of inflammatory nature (Weigert et al., 2010; De Palma et al., 2011; Kaneko et al., 2011). The mediatory role of chemerin observed in the immune responses may be associated with the pathogenesis of asthma and the inflammatory process itself (Zhou et al., 2018). Levels of chemerin in the synovial fluid and synovial membranes have been shown to be increased in the knees of osteoarthritis patients and those levels proportionately correlate with the severity of the disease (Ma et al., 2015).

Thyroid hormones (THs) are other key factors affecting almost all systems of the human body. Thus, special attention has been once again recently paid to the THs and THs-synthesis related enzymes - iodothyronine deiodinases (DIOs) - as important immune targets and modifiers of an inflammatory response (Korle 1999). There are also 
findings that both, the THs and DIOs may modulate the immune system and influence inflammatory processes by affecting phagocytosis, chemotaxis, oxidative stress or cytokine production (De Vito et al., 2012).

Deiodinase type 2 (DIO2) is an activating enzyme that converts the T4 prohormone into triiodothyronine T3 through deiodination at the phenolic ring. This enzyme is responsible for local cellular demands, rather than for circulating T3. Presence of DIO2 is observed in the central nervous system, pituitary, placenta and skin. Regulation of DIO2 expression and function is a complex process. For example, mRNA levels for DIO2 and its enzymatic activity are controlled by the mechanism of posttranslational regulation (Korle, 1999). DIO2 is stimulated by corticosteroids and growth factors (Courtin et al., 1990; Coppola et al., 2005). Some reports indicate a highly inducible nature of DIO2 during inflammation by the nuclear factor- $x \mathrm{~B}$ after treatment with bacterial lipopolysaccharide (LPS). In addition, its expression is similar to that of pro-inflammatory cytokines (Quan et al., 1998; Zeold et al., 2006). A study conducted by Kwakkel and others (Kwakkel et al., 2014) confirmed that DIO2 is upregulated during acute and chronic inflammation in macrophages and is correlated with IL-1 independently of the T3 serum levels. This may suggest that this enzyme plays a special role in the immune response. Therefore, DIO2 loss of function has significant metabolic implications, as $\mathrm{D} 2 \mathrm{KO}$ mice have been shown to gain more weight and adipose tissue, and that tissue also being a known source of the pro-inflammatory molecules (Marsisli et al., 2011).

In COPD, as in many other diseases, different biomarkers play a potential role in risk stratification, prediction of treatment responsiveness, monitoring of the disease and new drug investigation. Biomarkers are widely investigated in the sputum and blood of patients. A number of previous studies have examined concentration of different biomarkers in COPD; however, to the best of our knowledge, chemerin and deiodinase type 2 have not been studied in the serum of patients diagnosed with COPD. Markers involved in inflammation may play a crucial role in the development, mechanism and management of a disease, such as COPD. Measurements of inflammatory related molecules may be proposed as a biomarker with clinical utility in COPD.

Both DIO2 and chemerin are implicated in the immune and inflammatory processes that play a key role in the development of COPD.

In addition, it would appear that DIO2 plays a role in the determination of TH levels, with its inappropriate serum concentrations found in some patients diagnosed with COPD. Reduced TH serum levels have been shown in patients with acute exacerbations of COPD with subsequent recovery of $\mathrm{TH}$ s to various degrees, as the primary disease improves (Coskun et al., 2009; Cheng et al., 2016). Whereas chemerin (adipokine) is a product of adipose and there are data that adipokines may function as the link between adipocytes and COPD (Stanciu et al., 2009).

The purpose of this study was to determine whether the serum chemerin and DIO2 levels are linked with COPD, and to assess the role of these molecules as potential novel markers and/or risk factors of this disease.

\section{MATERIALS AND METHODS}

This study was carried out on a group of 80 subjects, including patients diagnosed with COPD and healthy volunteers - all of Caucasian ethnicity. The study was conducted at the Norbert Barlicki University Clinical Hospital No. 1 (Łódź, Poland), Department of Pulmonology and Allergology of the Medical University of Lodz, Poland, and later at an outpatient clinic. All of the patients underwent detailed diagnostics, which included a clinical examination, spirometry, gasometry, and anthropometry.

The group of patients with COPD comprised 50 people diagnosed in compliance with the Global Initiative for Chronic Obstructive Lung Disease (GOLD) document from 2015. All the patients were ex-smokers. Smoking history in the study group totaled between 25 and 40 years, and the average number of packs of cigarettes per year was 25 .

A total of 30 subjects, matched for age and sex, were selected among healthy community individuals invited to take part in the study based on the absence of diagnostic criteria.

Lung function was tested in clinically stable patients with the use of the LUNGTEST 1000 spirometer in a sitting position after a minimum of 15 -minute rest. The patients were instructed to avoid short-acting $\beta_{2}$-agonists at least 6 hours before testing and long-acting $\beta_{2}$-agonists at least 12 hours prior to the lung function test. Gasometry was measured based on arterial blood according to the required standards, and the test was performed using the Corning 348 blood gas analyzer (Ciba Corning, United States).

Body weight and height were measured for all of the patients with an intention to calculate the body mass index (BMI), while the waist and hip circumference enabled the calculation of the waist-to-hip ratio (WHR).

Exacerbations in the course of the study were excluded based on laboratory tests (blood cell count with a smear, C-reactive protein - CRP) and clinical presentation (absence of dyspnea, normal body temperature, no green sputum expectoration). Lung tumors were excluded using radiological modalities (X-ray, computed tomography).

All of the procedures were reviewed and approved by the Local Bioethics Committee. Written informed consent was obtained from all the participants of the study.

The venous blood samples were collected into sterile tubes $(2 \times 5 \mathrm{ml})$ without additives and stored at room temperature until formation of a surface clot (about 30 minutes); then, the samples were centrifuged for $15 \mathrm{~min}$ utes at approximately $1000 \times g$. After centrifugation, the serum was removed and aliquots were stored at $-80^{\circ} \mathrm{C}$. Sera samples were collected from patients participating in the study in the morning, not less than 12 hours after their last meal.

Chemerin and DIO2 were assessed using a commercially available Human DIO2 ELISA Kit (MyBiosourse, San Diego, CA, USA) and Human Chemerin Quantikine ELISA Kit (R\&D Systems, McKinley Place, MN, USA). All calculations were performed according to the instructions and protocols provided by the manufacturers. The absorbance of the samples was measured using Multiskan Ascent Microplate Photometer (Thermo Labsystems) at $\lambda=450 \mathrm{~nm}$. Analytical curves of the analyzed proteins were assessed to determine protein concentration. Serum DIO2 protein was presented in U/L, while serum chemerin protein levels in $\mathrm{ng} / \mathrm{ml}$. The detection range for human deiodinase type 2 , manufactured by Mybiosourse was $1.56 \mathrm{U} / \mathrm{L}$ to $50 \mathrm{U} / \mathrm{L}$. The detection range for human chemerin assay manufactured by $R \& D$ Systems was 48.0 to $142 \mathrm{ng} / \mathrm{ml}$. Both, the Intra-assay $\mathrm{CV}(\%)$ and Inter-assay $\mathrm{CV}(\%)$ were less than $15[\mathrm{CV}(\%)$ $=\mathrm{SD} /$ mean $\times 100]$. 
Table 1. Baseline characteristics of the study population, including antropometric and spirometric data

\begin{tabular}{|c|c|c|c|c|c|}
\hline \multicolumn{6}{|l|}{ Healthy controls } \\
\hline Parameters & Mean & Median & Minimum & Maximum & Standard deviation \\
\hline $\begin{array}{l}\text { Age (years) } \\
\text { Age women (yeras) } \\
\text { Age men (years) } \\
\text { BMI (kg/m2) } \\
\text { WHR } \\
\text { FEV1 } \\
\text { FEV1/NC } \\
\text { FVC }\end{array}$ & $\begin{array}{l}62.7 \\
62.2 \\
63.2 \\
25.0 \\
0.8 \\
102.8 \\
100.4 \\
109.4\end{array}$ & $\begin{array}{l}63 \\
62 \\
63.5 \\
25.2 \\
0.9 \\
102 \\
97.5 \\
109\end{array}$ & $\begin{array}{l}52 \\
53 \\
52 \\
17.7 \\
0.69 \\
87 \\
82 \\
85\end{array}$ & $\begin{array}{l}74 \\
74 \\
74 \\
33 \\
1.0 \\
116 \\
134 \\
128\end{array}$ & $\begin{array}{l}7 \\
7.1 \\
7.1 \\
4.6 \\
0.1 \\
6.0 \\
11.6 \\
11.1\end{array}$ \\
\hline \multicolumn{6}{|l|}{ Patients with COPD } \\
\hline $\begin{array}{l}\text { Age (years) } \\
\text { Age women (years) } \\
\text { Age men (years) } \\
\text { BMI (kg/m2) } \\
\text { WHR } \\
\text { FEV1 } \\
\text { FEV1/NC } \\
\text { FVC }\end{array}$ & $\begin{array}{l}65.7 \\
66.1 \\
65.5 \\
27.6 \\
1 \\
40.1 \\
65.5 \\
65.8\end{array}$ & $\begin{array}{l}65.5 \\
67 \\
65 \\
25.7 \\
1 \\
38.5 \\
60.5 \\
64.5\end{array}$ & $\begin{array}{l}50 \\
50 \\
52 \\
16.80 \\
0.75 \\
17 \\
39 \\
36\end{array}$ & $\begin{array}{l}81 \\
81 \\
78 \\
97.3 \\
1.3 \\
63 \\
96 \\
118\end{array}$ & $\begin{array}{l}8.2 \\
8 \\
8.4 \\
11.3 \\
0.1 \\
14.0 \\
16.6 \\
13.3\end{array}$ \\
\hline
\end{tabular}

Statistical analysis. All of the data analyses were performed using Statistica (version 12.0). A statistical analysis of the collected material included calculation of both, the descriptive and inferential statistics. The results are presented as percentages (\%) or means (M) with standard deviation ( \pm S.D.). The chi-square test and Mann-Whitney $U$ test were used to compare demographic variables (gender and age) between the patients and controls. The comparison of DIO1 and DIO3 concentration between the subjects with COPD and the controls was performed using the non-parametric Mann-Whitney U test. Pearson's correlation was calculated to evaluate the relationships between the analyzed protein levels and other variables. Statistical significance was defined as $p<0.05$ for all analyses.

\section{RESULTS}

The group of COPD patients consisted of $19(38 \%)$ females and $31(62 \%)$ males, with mean age of $65.7 \pm 8.2$ years (range: 50-81 years). Amongst the 30 volunteers from the control group, $16(53.33 \%)$ were female and $14(46.67 \%)$ male, with mean age of $62.7 \pm 7$ years (range: $52-74$ years). The baseline characteristics of the subjects, together with anthropometric and spirometric data, are summarized in Table 1 . There were no dif- ferences with respect to age $(z=1.61, p=0.1)$, gender $\left(\chi^{2}=1.79, p=0.1808\right)$, and BMI $(z=0.79, p=0.43)$. Differences between the COPD patients and the controls were observed in terms of WHR ( $z=3.81, p=0.000137)$. A significant reduction in FEV1, FV1/CV, and FVC in the COPD patients was acknowledged after a comparison with the controls, with $\mathrm{z}=-7.45108, p<0.001, \mathrm{z}=$ 7.05856, $p<0.0001$, and $z=-7.19838, p<0.0001$, respectively.

The obtained results confirmed that DIO2 levels were significantly higher in the serum of the patients suffering from COPD when compared to the healthy controls. Detailed data are presented in Table 2. We also investigated correlations between DIO2 and chemerin levels and the respiratory function parameters. No correlations were observed (data are presented in Table 3) between the investigated molecules levels and FEV1 values in controls (for DIO2 $\mathrm{r}=-0.15$, for chemrin $\mathrm{r}=-0.015$; $p>0.05$ ) and patients (for DIO2 $\mathrm{r}=-0.046$, for chemerin $\mathrm{r}=-0.13 ; p>0.05)$.

\section{DISCUSSION}

Currently, the focus of many research studies is placed on the significance of biomarkers in respiratory dysfunc-

Table 2. Statistical analysis describing differences in the protein levels between controls and COPD patients

\begin{tabular}{|c|c|c|c|}
\hline Variable & Healthy controls & COPD Patients & Statistical Analysis \\
\hline $\begin{array}{l}\text { DIO2 U/L } \\
\text { Mean } \\
\text { Median } \\
\text { Minimum } \\
\text { Maximum } \\
\text { Standard deviation }\end{array}$ & $\begin{array}{l}13.1 \\
10.5 \\
0.11 \\
69 \\
13.1\end{array}$ & $\begin{array}{l}50.3 \\
52.0 \\
3.74 \\
92.7 \\
23.2\end{array}$ & $\begin{array}{l}z=6.15 \\
P<0.00001\end{array}$ \\
\hline $\begin{array}{l}\text { Chemerin } \mathrm{ng} / \mathrm{ml} \\
\text { Mean } \\
\text { Median } \\
\text { Minimum } \\
\text { Maximum } \\
\text { Standard deviation }\end{array}$ & $\begin{array}{l}100.701 \\
96.063 \\
4.693 \\
272.19 \\
53.805 .5\end{array}$ & $\begin{array}{l}107.559 \\
86.278 \\
5.506 \\
579.641 \\
86.696\end{array}$ & $\begin{array}{l}z=-0.61 \\
P=0.54\end{array}$ \\
\hline $\begin{array}{l}\text { HS-CRP mg/L } \\
\text { Mean } \\
\text { Median } \\
\text { Minimum } \\
\text { Maximum } \\
\text { Standard deviation }\end{array}$ & $\begin{array}{l}3.816 \\
3.824 \\
1.14 \\
9.39 \\
1.959\end{array}$ & $\begin{array}{l}9.721 \\
8.919 \\
2.487 \\
22.807 \\
4.911\end{array}$ & $\begin{array}{l}z=5.62 \\
P<0.00001\end{array}$ \\
\hline
\end{tabular}

COPD, chronic obstructive pulmonary disease; DIO2, deiodinase type 2 , HS-CRP, high sensitive $\mathrm{C}$, reactive protein 
Table 3. Correlation between DIO2, chemerin protein levels and other parameters

\begin{tabular}{lllll}
\hline Healthy controls & $\mathrm{n}$ & $\mathrm{r}$ & Patients with COPD $\mathrm{n}$ & $\mathrm{R}$ \\
\hline DIO2 \& age & 30 & 0.236575 & 50 & -0.058321 \\
DIO2 \& BMI & 30 & 0.129686 & 50 & 0.181011 \\
DIO2 \& WHR & 30 & 0.426451 & 50 & 0.096871 \\
DIO2 \& chemerin & 30 & 0.031367 & 50 & -0.058315 \\
DIO2 \& HS-CRP & 30 & -0.203578 & 50 & -0.080361 \\
DIO2 \& FEV1 & 30 & -0.148490 & 50 & -0.045653 \\
DIO2 \& FEV1/VC & 30 & -0.059227 & 50 & 0.215806 \\
DIO2 \& FVC & 30 & -0.005650 & 50 & -0.129634 \\
\hline Chemerin \& age & 30 & 0.351187 & -0.009996 \\
Chemerin \& BMI & 30 & -0.306040 & 50 & -0.001541 \\
Chemerin \& WHR & 30 & -0.246334 & 50 & 0.071330 \\
Chemerin \& DIO2 & 30 & 0.031367 & 50 & -0.058315 \\
Chemerin \& HS-CRP & 30 & 0.269543 & 50 & -0.095915 \\
Chemrin \& FEV1 & 30 & -0.014631 & 50 & -0.127662 \\
Chemerin \& FEV1/VC & 30 & -0.286143 & 50 & -0.191124 \\
Chemerin \& FVC & 30 & 0.365811 & 50 & -0.005087 \\
\hline
\end{tabular}

tions. This study was intended to test serum concentrations. The authors compared serum molecule levels, such as deiodinase type 2 and chemerin, in patients diagnosed with COPD. According to the latest scientific data, DIO2 is not only involved in TH synthesis, but also in the immune- and inflammation-related mechanisms (Kwakkel et al., 2014). The investigated molecules may play an important role in COPD, i.e. a disease with inflammatory mechanisms. This study demonstrated that DIO2 and chemerin are detectable in the serum of patients with COPD and in healthy controls. The main finding of this study is that DIO2 serum levels are highly increased in the patients suffering from COPD. To the best of our knowledge, and due to the fact that we were not able to find any other data on DIO2 concentration in COPD, this is the first study addressing and investigating this particular issue.

The investigated molecule was of interest in terms of other pulmonary-related diseases. Barca-Mayo and others (Barca-Mayo et al., 2011) had investigated the role of DIO2 in response to acute lung injury (ALI) in epithelial and pulmonary endothelial cells. Similar to our results, both, the DIO2 immunoreactivity and enzymatic activity, had increased. This suggests that higher levels of DIO2 may play a protective role against the lung injury, as the injury was more severe in D2 knock-out mice (D2KO) (Barca-Mayo et al., 2011). A significant increase in the gene and protein levels was also found in the lung tissue in a murine ALI model. In addition, an allele of the Thr92Ala single nucleotide polymorphism, related to a higher expression level, had a protective function in severe sepsis and severe sepsis-associated ALI (Ma et al., 2011). The protective effect may be explained in a multidirectional manner. One mechanism may include the effects of DIO2 on the TH levels. It is widely known that a severe illness, such as for example acute lung injury, is characterized by a non-thyroidal illness known as decreased T4 and T3 serum levels (Pappa et al., 2011). DIO2 may work as a compensatory mechanism during the injury when hepatic/renal DIO1 production is reduced. An increase in DIO2 may be considered a protective mechanism against inflammation. DIO2 could be upregulated as part of the inflammatory pathway via $\mathrm{NF}-x \mathrm{~B}$, which is also strongly involved in acute lung injury and COPD (de Vries et al., 2014). Marked upregulation of DIO2 expression was observed by Kwakkel and others (Kwakkel et al., 2014) during acute and chronic inflammation. These researchers had suggest that DIO2 is important for macrophage phagocytic capacity. Increased DIO2 levels also result in higher TH levels, which are known to enhance the following elements of inflammation: respiratory bursts, iNOS activation, cytokine production, and bacterial killing (Chen et al., 2012). The local role of DIO2 in thyroid hormone transformation must be of importance for the inflammatory response and favors the innate immune response, as DIO2 deficiency results in proinflammatory expression (Barca-Mayo et al., 2011; Kwakkel et al., 2014). Wittmann and others (Wittmann et al., 2014), who had observed a cell type-specific and highly inducible nature of DIO2 expression by inflammation, claimed that DIO2 was involved in inflammation. Moreover, according to Chen and others (Chen et al., 2012), suppression of selenoproteins, such as DIO2, resulted in strong pro-inflammatory effects with increased expression of interleukin-1 and cyclooxygenase type 2 .

To shortly sum up, an increase in DIO2 levels in COPD may by a complex issue, associated with TH synthesis, modulation and control of the immune function.

Chemerin was yet another molecule of interest in our study. This adipokine demonstrates immunomodulating activity and is regulated by proinflammatory cytokines, such as TNF- $\alpha$, IL-6, IL1 $\beta$ (Kaur et al., 2010).

The results of our study did not confirm any significant differences in the chemerin levels between patients suffering from COPD and the healthy controls. According to the best of our knowledge, based on the available literature, there are only three studies estimating chemerin in COPD. The results of these studies are not in line with our results, hence an open discussion and further exploration of the role of chemerin in COPD are necessary. Li and others (Li et al., 2016) used ELISA to detect plasma chemerin levels in COPD. These researchers had observed that chemerin levels might be a prognostic factor for COPD and might reflect lipid metabolism. The patients enrolled in that study were divided into two groups, taking into account the body mass index (thin group with $\mathrm{BMI} \leq 18.5 \mathrm{~kg} / \mathrm{m}^{2}$ and normal group with $\mathrm{BMI} \geq 18.5 \mathrm{~kg} / \mathrm{m}^{2}$. The collected data had shown differences in the chemerin levels between the patients and heathy controls. When compared with the control group, plasma levels of chemerin were elevated in the COPD group during acute exacerbation and remission stages. The plasma levels of chemerin in the normal group were 
lower in comparison with the thin group. The plasma levels of chemerin in patients suffering from COPD, who were hospitalized for half a year or that had died, were higher than the plasma levels in COPD patients without hospitalization. In addition, there was a correlation between chemerin and lipid levels, such as the total cholesterol, triglyceride, and high-density protein levels. Similarly, an increase in the plasma levels of chemerin in patients diagnosed with COPD and the relationship with total cholesterol and triglyceride levels were confirmed in the second study by Boyuk and others (Boyuk et al., 2015).

The involvement of chemerin and chemerin-related signal was also confirmed in a murine cigarette smoke (CS) COPD. The obtained results revealed that subacute and chronic CS exposure caused increased protein levels of the ChemR23 ligand and chemerin in the bronchoalveolar lavage (BAL) fluid of wild-type (WT) mice. Higher levels of the above-indicated molecules were positively correlated with massive accumulation of inflammatory cells, including neutrophils, monocytes or dendritic cells. In contrast, the inflammatory process was diminished in the BAL fluid and lungs of ChemR23 knockout mice (Demoor et al., 2011).

Results confirm that the two molecules investigated in our study are induced by the proinflammatory cytokines characteristic for COPD, such as TNF- $\alpha$, IL-6, IL-1 $\beta$, and are positively correlated (Kaur et al., 2010; Kwakkel et al., 2014). Therefore, we aimed to find if there is a correlation between DIO2 and chemerin levels in COPD. Nevertheless, the obtained results did not reveal any correlation between the molecules and their role in the mechanism involved in COPD. We have not observed correlation between DIO2, chemerin and the severity of the disease. Nevertheless, COPD is characterized by persistent inflammation. Increased levels of DIO2 may result in a higher production and release of proinflammatory cytokines, promoting the occurrence and development of an inflammatory process.

\section{LIMITATIONS}

The study presented here has several limitations that need to be noted. Patients in this study continued to take their prescribed COPD medications during the entirety of the study period. Nevertheless, a comprehensive search of literature relevant to the subject matter did not yield any information that could link DIO2/ chemerin levels with various pharmacotherapies used for treatment of COPD. Yet another notable limitation of this study pertains to the lack of significant information about the patients' thyroid hormone status. Undoubtedly, data demonstrating the patients' TH serum concentrations could add valuable information about the possible association(s) between DIO2 and the thyroid hormones.

\section{CONCLUSION}

COPD is considered to be a disease of systemic inflammation. Identification of biomarkers related to this process is a developing field. Chemerin and DIO2 are significantly linked to inflammation. The study presented here confirmed an association of circulating DIO2 in COPD. While recognizing that more studies need to be conducted in this subject matter, the data presented here continues to cautiously support our initial hypothesis that DIO2 may play a role in COPD, including in its inflammatory mechanism. However, other mechanisms might also be considered as responsible for that process. Further studies are necessary to investigate the biological function of DIO2 in COPD and its role in the occurrence and development of the disease. Nevertheless, we did not confirm the role of chemerin in the disease in question. Further research and studies on larger populations are needed to prove the results for both molecules.

\section{Conflict of interest}

The authors declare no conflict of interest

\section{REFERENCES}

Barca-Mayo O, Liao XH, DiCosmo C, Dumitrescu A, Moreno-Vinasco L, Wade MS, Sammani S, Mirzapoiazova T, Garcia JG, Refetoff S, Weiss RE (2011) Role of type 2 deiodinase in response to acute lung injury (ALI) in mice. Proc Natl Acad Sci U S A 108: E1321E1329. https//doi.org/10.1073/pnas.1109926108

Boyuk B, Guzel EC, Atalay H, Guzel S, Mutlu LC, Kucukyalçin V (2015) Relationship between plasma chemerin levels and disease severity in COPD patients. Clin Respir 9: 468-474. https//doi.org/ $10.1111 /$ crj.12164

Chen Y, Sjölinder M, Wang X, Altenbacher G, Hagner M, Berglund P, Gao Y, Lu T, Jonsson AB, Sjölinder H (2012) Thyroid hormone enhances nitric oxide-mediated bacterial clearance and promotes survival after meningococcal infection. PLoS One 7: e41445. https// doi.org/10.1371/journal.pone.0041445

Coppola A, Meli R, Diano S (2005) Inverse shift in circulating corticosterone and leptin levels elevates hypothalamic deiodinase type 2 in fasted rats. Endocrinology 146: 2827-2833. https//doi.org/10.1210/ en.2004-1361

Courtin F, Gavaret JM, Toru-Delbauffe D, Pierre M (1990) Induction of 5'-deiodinase activity in rat astroglial cells by acidic fibroblast growth factor. Brain Res Dev Brain Res 53: 237-242. https://doi. org/10.1016/0165-3806(90)90012-N

De Palma G, Castellano G, Del Prete A, Sozzani S, Fiore N, Loverre A, Parmentier M, Gesualdo L, Grandaliano G, Schena FP (2011) The possible role of ChemR23/Chemerin axis in the recruitment of dendritic cells in lupus nephritis. Kidney Int 79: 1228-1235. https://doi.org/10.1038/ki.2011.32

De Vito P, Balducci V, Leone S, Percario Z, Mangino G, Davis PJ, Davis FB, Affabris E, Luly P, Pedersen JZ, Incerpi S (2012) Nongenomic effects of thyroid hormones on the immune system cells: New targets, old players. Steroids 77: 988-995. https//doi. org/10.1016/j.steroids.2012.02.018

de Vries EM, Kwakkel J, Eggels L, Kalsbeek A, Barrett P, Fliers E, Boelen A (2014) NFxB signaling is essential for the lipopolysaccharide-induced increase of type 2 deiodinase in tanycytes. Endocrinology 155: 2000-2008. https//doi.org/10.1210/en.2013-2018

Demoor T, Bracke KR, Dupont LL, Plantinga M, Bondue B, Roy MO, Lannoy V, Lambrecht BN, Brusselle GG, Joos GF (2011) The role of ChemR23 in the induction and resolution of cigarette smoke-induced inflammation. J Immunol 186: 5457-5467. https//doi.org/ 10.4049/jimmunol.1003862

Fantuzzi G (2005) Adipose tissue, adipokines, and inflammation. $J$ Allergy Clin Immunol 115: 911-919. https//doi.org/10.1016/j.peptides.2014.09.019

Fatima SS, Rehman R, Baig M, Khan TA (2014) New roles of the multidimensional adipokine: chemerin. Peptides 62: 15-20. https// doi.org/10.1016/j.peptides.2014.09.019

Kaneko K, Miyabe Y, Takayasu A, Fukuda S, Miyabe C, Ebisawa M, Yokoyama W, Watanabe K, Imai T, Muramoto K, Terashima Y, Sugihara T, Matsushima K, Miyasaka N, Nanki T (2011) Chemerin activates fibroblast-like synoviocytes in patients with rheumatoid arthritis. Artbritis Res Ther 13: R1. https//doi.org/10.1038/ki.2011.32

Kaur J, Adya R, Tan BK, Chen J, Randeva HS (2010) Identification of chemerin receptor (ChemR23) in human endothelial cells: chemerin-induced endothelial angiogenesis. Biochem Biophys Res Commun 391: 1762-1768. https//doi.org/10.1016/j.bbrc.2009.12.150

Köhrle J (1999) Local activation and inactivation of thyroid hormones: the deiodinase family. Mol Cell Endocrinol 151: 103-119. https://doi. org/10.1016/S0303-7207(99)00040-4

Kwakkel J, Surovtseva OV, de Vries EM, Stap J, Fliers E, Boelen A (2014) A novel role for the thyroid hormone-activating enzyme type 2 deiodinase in the inflammatory response of macrophages. Endocrinology 155: 2725-2734. https//doi.org/10.1210/en.2013-2066

Li C, Yan L, Song J (2016) Plasma level of chemerin in COPD patients and the relationship between chemerin and lipid metabolism. Zhong nan da xue xue Bao. Yi xue ban = Journal of Central South University. Medical Sciences 41: 676-83. https//doi.org/10.11817/j.issn.16727347.2016.07.003 (in Chinese) 
López-Campos JL, Tan W, Soriano JB (2016) Global burden of COPD Respirology 21: 14-23. http//doi.org/10.1111/resp.12660

Ma J, Niu DS, Wan NJ, Qin Y, Guo CJ (2015) Elevated chemerin levels in synovial fluid and synovial membrane from patients with knee osteoarthritis. Int J Clin Exp Pathol 8: 13393-13398. PMCID: 4680491

Ma SF, Xie L, Pino-Yanes M, Sammani S, Wade MS, Letsiou E, Siegler J, Wang T, Infusino G, Kittles RA, Flores C, Zhou T, Prabhakar BS, Moreno-Vinasco L, Villar J, Jacobson JR, Dudek SM, Garcia JG (2011) Type 2 deiodinase and host responses of sepsis and acute lung injury. Am J Respir Cell Mol Biol 45: 1203-1211. https// doi.org/10.1165/rcmb.2011-0179OC

Mariani F, Roncucci L (2015) Chemerin/chemR23 axis in inflammation onset and resolution. Inflamm Res 64: 85-95. https//doi.org/ 10.1007/s00011-014-0792-7

Marsili A, Aguayo-Mazzucato C, Chen T, Kumar A, Chung M, Lunsford EP, Harney JW, Van-Tran T, Gianetti E, Ramadan W, Chou C, Bonner-Weir S, Larsen PR, Silva JE, Zavacki AM (2011). Mice with a targeted deletion of the type 2 deiodinase are insulin resistant and susceptible to diet induced obesity. PLoS One 6: e20832. https//doi.org/10.1371/journal.pone.0020832

Mayer AS, Newman LS (2001) Genetic and environmental modulation of chronic obstructive pulmonary disease. Respir Physiol 128: 3-11. https://doi.org/10.1016/S0034-5687(01)00258-4

Pappa TA, Vagenakis AG, Alevizaki M (2011) The nonthyroidal illness syndrome in the non-critically ill patient. Eur J Clin Invest 41: 12-20. https://doi.org/10.1111/j.1365-2362.2010.02395.x

Quan N, Whiteside M, Herkenham M (1998) Time course and localization patterns of interleukin-1beta messenger RNA expression in brain and pituitary after peripheral administration of lipopolysaccharide. Neuroscience 83: 281-93. https://doi.org/10.1016/S03064522(97)00350-3

Sinden NJ, Stockley RA (2010) Systemic inflammation and comorbidity in COPD: a result of 'overspill' of inflammatory mediators from the lungs? Review of the evidence. Thorax 65: 930-936. https//doi.org/ $10.1136 /$ thx.2009.130260

Weigert J, Obermeier F, Neumeier M, Wanninger J, Filarsky M, Bauer S, Aslanidis C, Rogler G, Ott C, Schäffler A, Schölmerich J, Buechler C (2010) Circulating levels of chemerin and adiponectin are higher in ulcerative colitis and chemerin is elevated in Crohn's disease. Inflamm Bowel Dis 16: 630-637. https//doi.org/10.1002/ ibd. 21091

Wittmann G, Harney JW, Singru PS, Nouriel SS, Reed Larsen P, Lechan RM (2014) Inflammation-inducible type 2 deiodinase expression in the leptomeninges, choroid plexus, and at brain blood vessels in male rodents. Endocrinology 155: 2009-2019. https//doi. org/10.1210/en.2013-2154

Zeöld A, Doleschall M, Haffner MC, Capelo LP, Menyhért J, Liposits Z, da Silva WS, Bianco AC, Kacskovics I, Fekete C, Gereben B (2006) Characterization of the nuclear factor-kappa B responsiveness of the human dio2 gene. Endocrinology 147: 4419-4429. https// doi.org/10.1210/en.2005-1608

Zhou Q, Fu Y, Hu L, Li Q, Jin M, Jiang E (2018) Relationship of circulating chemerin and omentin levels with Th17 and Th9 cell immune responses in patients with asthma. J Asthma 55: 579-587. https//doi.org/10.1080/02770903.2017.1355378 